\title{
AN EXPERIMENTAL PARAMETRIC STUDY OF GEOMETRIC, REYNOLDS NUMBER, AND RATIO OF SPECIFIC HEATS EFFECTS IN THREE-DIMENSIONAL SIDEWALL COMPRESSION SCRAMJET INLETS AT MACH 6
}

\author{
Scott D. Holland* and Kelly J. Murphy** \\ NASA Langley Research Center \\ Hampton, VA 23681
}

\begin{abstract}
$\underline{\text { Abstract }}$
Since mission profiles for airbreathing hypersonic vehicles such as the National Aero-Space Plane include single-stage-to-orbit requirements, real gas effects may become important with respect to engine performance. The effects of the decrease in the ratio of specific heats have been investigated in generic three-dimensional sidewall compression scramjet inlets with leading-edge sweep angles of 30 and 70 degrees. The effects of a decrease in ratio of specific heats were seen by comparing data from two facilities in two test gases: in the Langley Mach $6 \mathrm{CF}_{4}$ Tunnel in tetrafluoromethane (where $\gamma=1.22$ ) and in the Langley 15-Inch Mach 6 Air Tunnel in perfect gas air (where $\gamma=1.4)$. In addition to the simulated real gas effects, the parametric effects of cowl position, contraction ratio, leading-edge sweep, and Reynolds number were investigated in the 15-Inch Mach 6 Air Tunnel. The models were instrumented with a total of 45 static pressure orifices distributed on the sidewalls and baseplate. Surface streamline patterns were examined via oil flow, and schlieren videos were made of the external flow field. The results of these tests have significant implications to ground based testing of inlets in facilities which do not operate at flight enthalpies.
\end{abstract}

\section{$\underline{\text { Nomenclature }}$}

$\mathrm{Cp}$ pressure coefficient, $\frac{2}{\gamma \mathrm{M}_{\infty}^{2}}\left(\frac{\mathrm{p}}{\mathrm{p}_{\infty}}-1\right)$

$\mathrm{CR}$ contraction ratio, $\mathrm{W} / \mathrm{g}$

* Research Engineer, Experimental Hypersonics Branch, Member AIAA.

** Aerospace Engineer, Experimental Hypersonics Branch.

Copyright (C) 1993 by the American Institute of Aeronautics and Astronautics, Inc. No copyright is asserted in the United States under Title 17, U.S. Code. The U.S. Government has a royaltly-free license to exercise all rights under the copyright claimed herein for Governmental purposes. All other rights are reserved by the copyright owner.

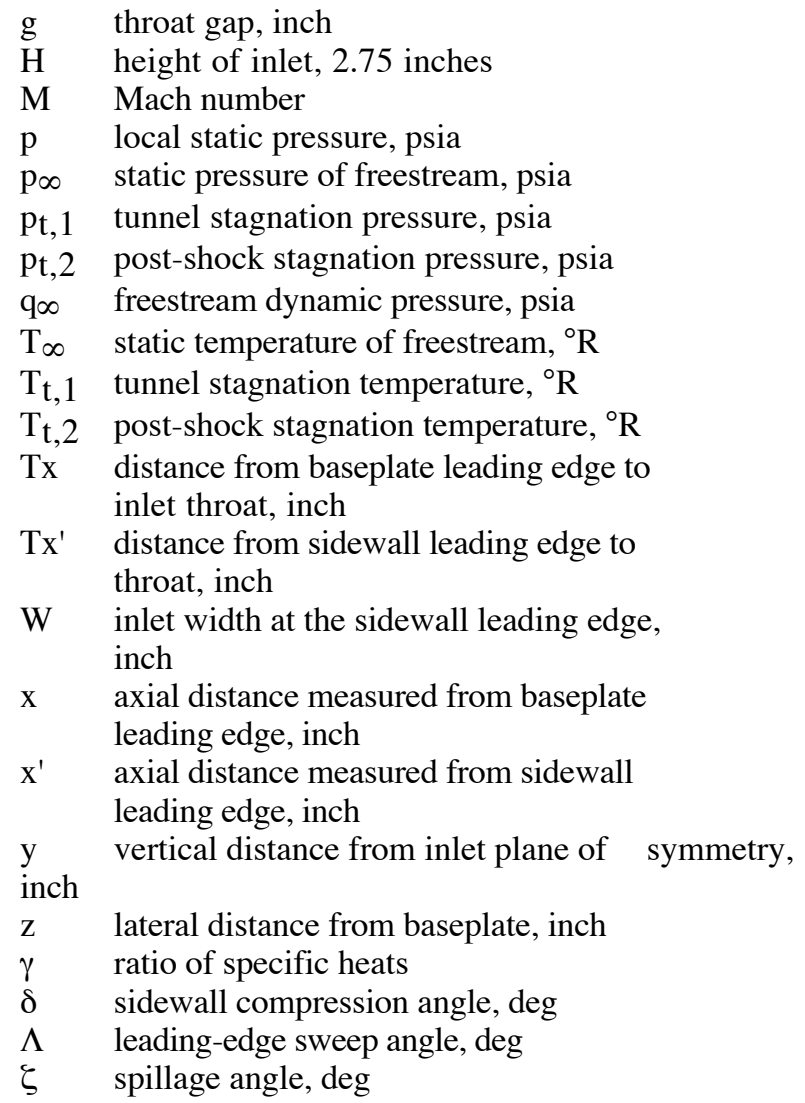

\section{$\underline{\text { Introduction }}$}

Hypersonic propulsion for airbreathing vehicles such as the National Aero-Space Plane (X-30) is proposed to be accomplished with highly integrated supersonic combustion ramjets (e.g. Refs. 1-2). The advantages of propulsion-airframe integration have been well recognized for many years (e.g. Ref. 3). This concept makes use of the forebody bow shock to precompress the flow prior to entering the engine (Fig. 1 ). It is anticipated that the boundary layer at the inlet entrance on a full scale hypersonic vehicle would be large compared to the inlet height. (Computational results have been presented in Ref. 4 for inflow boundary layers as large as $20 \%$ of the inlet height.) As a result, further turning in the vertical direction, as in two-dimensional inlets, would greatly increase the probability of large scale separation regions at the 
entrance of the inlet due to shock-boundary layer interactions. It is important to note that the scale and nature of these interactions depend strongly upon the state of the boundary layer; this series of tests is for a laminar boundary layer.

The present configuration (Fig. 2) represents a three-dimensional inlet, wherein further compression is accomplished in the horizontal direction by wedgeshaped sidewalls, reducing the total in-plane turning the flow must encounter. The sidewall leading edges are swept both to reduce aerothermal loads, hence cooling requirements on the leading edge, and to increase inlet flow spillage to aid in starting the inlet at lower Mach numbers. The generic three-dimensional sidewall compression inlets used in these tests have been studied for several years. (Northam and Anderson ${ }^{5}$ trace the development of scramjet research at NASA Langley). Trexler ${ }^{6-10}$ has performed much of the earlier work on this type of inlet. The sweep has been shown (Ref. 11) to induce a component of velocity parallel to the leading edge. For an aft swept leading edge, this has the effect of turning the flow away from the forebody plane, spilling it out ahead of the cowl. It was also demonstrated that as the Mach number is increased, the sidewall shock angles become smaller, effectively reducing the spillage window, increasing the mass capture, and making the inlet more efficient at high Mach numbers. This provides variable geometry characteristics for a fixed geometry inlet over a wide Mach number range.

Since mission profiles for hypersonic vehicles employing scramjets include regions of the trajectory where real gas effects may become important, the present work examines the effects of the decrease in the ratio of specific heats such as occurs at temperatures sufficiently high to dissociate the flow about the vehicle. The decrease in ratio of specific heats is simulated by comparing data previously obtained (Ref. 12) in tetrafluoromethane $(\gamma=1.22)$ with the present data from perfect gas air $(\gamma=1.4)$. In addition to the simulated real gas effects, the parametric effects of leading-edge sweep, contraction ratio, cowl position, and Reynolds number were investigated in the 15-Inch Mach 6 Air Tunnel at the NASA Langley Research Center. The generic models were instrumented with a total of 45 pressure orifices distributed on the sidewalls and baseplate and were designed to ingest a known inflow (freestream), rather than model the forebody/inlet interactions, which may be configuration specific. Flow visualization of the external flow field was provided by schlieren videos; surface streamline patterns were examined via oil flow.

\section{Apparatus and Test}

\section{Model Description}

Figure 3 shows photographs of the inlet models, and Figure 4 presents dimensioned drawings. Leading- edge sweeps of 30 and 70 degrees were chosen to represent both moderately and highly swept cases. As a result of a trade-off study 9 , the sidewall compression angle, $\delta$, was fixed at 6 degrees (Fig. 5). This represents a compromise between larger compression angles leading to stronger internal shocks with increased probability of boundary-layer separation and smaller compression angles leading to weaker internal shocks but requiring the inlet to be longer, yielding an undesirable size and weight increase, to obtain the same compression.

Both models were machined of aluminum with a sidewall height of $2.75 \mathrm{in}$. and sidewall leading edge diameter of $0.010 \mathrm{in}$. The baseplate and cowl each had leading edge diameters of 0.015 in. and $10^{\circ}$ of external compression (Fig. 4). The models were injected into the tunnel in an inverted orientation with the cowl on top; all configurations were uncooled. A flat plate was used to represent the forebody surface and will be referred to as the baseplate. Since the forebody boundary layer is not modeled, the configuration is said to be uninstalled.

The $30^{\circ}$ sidewall model was originally designed for a parametric study of inlet starting performance 10 and was instrumented only to the extent necessary to determine if unstart had occurred. A number of pressure taps were added to the $30^{\circ}$ model, $70^{\circ}$ sidewalls were fabricated, and the models were then tested in the 22Inch Helium Tunnel at Mach 18.1 and 21.6 ${ }^{11}$. Since these models have been adapted from previous test programs, the instrumentation density and location are not optimal. A total of 45 static orifices (0.040 in. inside diameter) are arranged in single arrays along the centerlines of the baseplate and sidewalls and on the sidewall at $\mathrm{y} / \mathrm{H}=0.13$ and at $\mathrm{y} / \mathrm{H}=0.87$ as shown in Figure 4.

The contraction ratio is defined as the ratio of the inlet entrance area to the throat area. For inlets of constant height, this reduces to the ratio of inlet entrance width to the throat gap, W/g (see Fig. 5). The contraction ratio could be varied between the runs by laterally moving the sidewalls. The cowl position could also be changed between runs. For the present study, the cowl was placed at the throat entrance (referred to as 0\% cowl) and forward of the throat by $25 \%$ of the distance between the throat entrance and the sidewall leading edge ( $25 \%$ cowl). 


\section{Facility Description}

The models were tested in the 15-Inch Mach 6 Air Tunnel at the NASA Langley Research Center. A detailed description of this facility and related instrumentation is presented in Ref. 13. Figure 6 presents a schematic of the tunnel, illustrating its major components. The 15-Inch Mach 6 is a blowdown facility which uses heated dry air as the test gas. It has an open jet test section with a nozzle exit diameter of $14.5 \mathrm{in}$. and test chamber diameter of $5 \mathrm{ft}$. A hydraulically operated model injection mechanism can inject the model into the flow in 0.5 seconds. The maximum run time for this facility is 90 seconds, but typical run times for these tests were 15 seconds.

\section{Instrumentation, Data Reduction, and Uncertainty}

The reservoir pressure $\mathrm{p}_{\mathrm{t}, 1}$ was measured with two high accuracy ( $\pm 0.04 \%$ full scale) silicon sensors having a full scale rating of 500 psia or 200 psia, depending on the operating condition of the tunnel. The reservoir temperature $T_{t, 1}$ was measured with two iron-constantan thermocouples inserted through the wall of the settling chamber, positioned near the center of the chamber. The pitot pressure of the flow in the test section $\mathrm{p}_{\mathrm{t}, 2}$ was measured by a flat-faced cylindrical probe, linked to an electronically scanned silicon sensor. A second pressure sensor was used to measure the surface pressures on the model. The two pressure modules each contain 32 sensors and were located at the base of the model strut to minimize the tubing length between the pressure orifices on the model and the module. A pneumatically controlled slide allows the transducers to be calibrated in-situ. This in-situ calibration consisted of applying three known pressures (vacuum levels), chosen to span the range of the expected measured pressures. A sample rate of 20 samples per second was obtained for 64 channels. Model and pitot pressures were measured using modules rated for a maximum pressure of 5 psia.

Schlieren videos were made of each run for flow visualization of the external flow field in the region of the entrance plane and cowl. The view is a profile of the inlet, shown in an inverted orientation with the cowl on top.

Since the pressure sensor system contains its own signal processing system, it is interfaced directly to a data acquisition computer. Measured values of $\mathrm{P}_{\mathrm{t}, 1}$ and $\mathrm{T}_{\mathrm{t}, 1}$ are believed to be accurate to within $\pm 2 \%$. Based on manufacturer specifications, values of $\mathrm{P} / \mathrm{P}_{\infty}$ are estimated to be accurate to within $\pm 5 \%$ at the lowest freestream static pressures and to within $\pm 1 \%$ at the highest freestream static pressures. Repeatability was found to be approximately $\pm 3 \%$.

\section{Test Conditions}

Tests were performed at Mach 6 for reservoir pressures and temperatures shown in Table 1. The freestream Reynolds numbers for these conditions were
$0.5 \times 10^{6}, 2 \times 10^{6}$, and $4 \times 10^{6}$ per foot with the corresponding freestream static pressures of 0.03 psia, $0.08 \mathrm{psia}$, and $0.15 \mathrm{psia}$, respectively. The freestream ratio of specific heats was 1.4. The test matrix is given in Tables 2 and 3.

\section{$\underline{\text { Results and Discussion }}$}

Despite the relatively simple geometry, threedimensional sidewall compression inlets produce a highly complex flow field, of which shock/shock, shock/boundary layer, and corner flow are among the interactions. It is therefore useful to develop a simplified model of the flow field. A brief discussion of inlet interactions based solely on inviscid considerations is first presented to form this model. This is followed by a discussion of the experimental results, organized according to the stated parametric effects.

\section{$\underline{\text { Inviscid Flow Model }}$}

A modification to two-dimensional oblique shock theory to accommodate the three-dimensional effects of leading-edge sweep has been presented in Ref. 11. This method allows quick, computationally inexpensive studies of parametric effects of leading-edge sweep, contraction ratio, and cowl position on the mass capture and performance of a three-dimensional inlet for the limiting case of inviscid flow. As such, the method is useful as a preliminary design tool and in that it provides a model of the simplified flow field, i.e. without viscous interactions. The direct effects of viscous interactions are then evident in the data as deviations from the idealized model. Since this method has been used in the present work to predict qualitatively the inviscid effects of contraction ratio and leading-edge sweep angle on inlet flow phenomena, a summary of the parametric effects identified in that work are presented herein.

In order to achieve efficient engine operation, it is necessary that an inlet start (that is, establish supersonic flow throughout) at a low inflow Mach number. The shock structure which develops from the swept sidewall leading edges has been demonstrated to induce a velocity component toward the cowl. When combined with an aft cowl placement, this provides a window for flow spillage to aid in inlet starting. As the Mach number is increased, it has been further demonstrated that both the induced spillage decreases and the spillage window partially closes (due to shocks lying closer to the sidewalls). This yields improved mass capture and makes the inlet more efficient at higher Mach numbers. Thus, the three-dimensional sidewall compression inlet appears to possess variable geometry characteristics in a fixed geometry inlet. When the cowl is placed forward of the throat, the mass capture of the inlet can be improved but at a cost of increased starting Mach number. The details of this 
modified oblique shock theory as well as a full discussion of the parametric effects are presented in Ref. 11.

\section{Experimental Results}

Due to the large number of parameters considered in this study, it is convenient to define a set of baseline values and to discuss all parametric effects as deviations from this baseline configuration. The baseline configuration is defined as a contraction ratio of 3 , leading-edge sweep angle of $30^{\circ}$, cowl position of $0 \%$, Reynolds number of $0.5 \times 10^{6} / \mathrm{ft}$, and ratio of specific heats of 1.4. This configuration was selected as the baseline because it represents the least constrictive configuration tested (i.e. sidewalls furthest apart, cowl furthest aft) and hence was the easiest to start. Changing the cowl position or contraction ratio from this configuration imposed conditions which, while potentially improving inlet performance, increased the probability of inlet unstart.

A detailed discussion of the pressure distributions for the baseline configuration will be presented first in the form of plots which superimpose the pressure distributions from the three arrays on the sidewall. The effects of the geometric variables, cowl position, contraction ratio, and leading-edge sweep angle, on the baseplate and sidewall centerline will be presented next. Finally the effects of Reynolds number and ratio of specific heats $(\gamma)$ will be examined. An emphasis will be placed on the analysis involving the comparison between data obtained in air and $\mathrm{CF}_{4}$ to simulate real gas effects via variation in $\gamma$.

Baseline Configuration. Figure 7 presents the sidewall pressure distribution for the baseline conditions discussed above. The centerline sidewall pressure distribution indicates the presence of reflecting oblique shocks, characteristic of a started inlet. The first pressure rise is seen at $\mathrm{x}^{\prime} / \mathrm{Tx}^{\prime}=0.76$ and continues through $\mathrm{x}^{\prime} / \mathrm{Tx}^{\prime}=0.95$, very near the throat entrance. Oblique shock theory, modified for the effect of leadingedge sweep, predicts the leading edge shocks to cross at the centerline and impinge on the sidewalls at approximately $\mathrm{x}^{\prime} / \mathrm{Tx}^{\prime}=0.87$. This shock impingement location is evident in the oil flow model for this configuration as seen in Figure 8. Ahead of this shock impingement, a region of upstream influence is observed which corresponds to the gradual pressure rise in the experimental data (Fig. 7) through the shock impingement region. Note that the sweep of the shock has been preserved through the shock crossing and impingement. A sharp drop in pressure is observed in Figure 7 between $\mathrm{x}^{\prime} / \mathrm{Tx}^{\prime}=0.95$ and $\mathrm{x}^{\prime} / \mathrm{Tx}^{\prime}=1.05$, indicating flow expansion around the shoulder into the throat. At $\mathrm{x}^{\prime} / \mathrm{Tx}^{\prime}=1.23$, still in the constant area throat region, another pressure rise is observed indicating that the flow has encountered a second reflected shock. Note that as previously mentioned, the instrumentation density was not optimal, therefore absolute pressure maxima and minima may have occurred between the pressure orifices. The pressure distribution at $\mathrm{y} / \mathrm{H}=0.13$ follows the same trend leading up to the throat entrance but is slightly below the centerline curve. (Kutschenreuter, et al. ${ }^{14}$ hypothesized the existence of a centered expansion originating from the shock sheet/baseplate interface (Fig. 9) to insure that the flow vector downstream of the shock sheet lies not only in the plane of the upturned flow but also in the plane of the baseplate. This permits the flow vector to be positioned in both planes and predicts pressures near the baseplate to be lower (as seen in Fig. 7) than in the center of the inlet where end effects are of lesser importance.) The orifices at $\mathrm{y} / \mathrm{H}=0.87$ indicate a pressure relief due to the spillage, and the associated pressure distribution is also slightly below the centerline values.

Cowl Position. For a fixed contraction ratio and leading-edge sweep angle, the effects of cowl position on inlet compression are presented in Figure 10. For the baseline configuration, Figure 10a shows the pressure distribution along the baseplate for the $0 \%$ and $25 \%$ cowl positions. There is virtually no change in the measured pressures with a forward cowl movement, indicating that the baseplate of the inlet appears to be out the domain of influence of the cowl for this geometry. The sidewall pressures for the same configuration (Fig. 10b) show that while the forward cowl movement seems to have little effect on the first shock impingement location, a noticeable effect is observed on the expansion region at the throat entrance. High pressure fluid that would have spilled out ahead of the cowl placed at $0 \%$ (the nominal position) is now captured by the inlet with the cowl placed at $25 \%$. This increase in mass capture is manifested through a slightly higher pressure beyond the sidewall throat entrance. No reflected shock pattern can be resolved in the throat region for the $25 \%$ cowl position. Cowl placement in this range has a minimal effect on the pressure distributions for both the baseplate and the sidewall centerline.

In contrast, the cowl position for this inlet at a contraction ratio of 5 (Fig. 11) was found to have a dramatic effect on the entire internal flow field of the inlet. Figure $11 \mathrm{a}$ presents the axial pressure distributions on the baseplate for both $0 \%$ and $25 \%$ cowl at a leading-edge sweep angle of $30^{\circ}$ and a Reynolds number of $0.5 \times 10^{6} / \mathrm{ft}$. At $0 \%$ cowl (baseline), the trends in the pressure ratios are indicative of a started inlet. Drastically different pressure levels are observed for the forward cowl position. With the cowl in the forward position, a larger inlet throat area is now required to pass the captured mass flow through the inlet at this Mach number and the inlet unstarts, producing dramatic pressure increases throughout the inlet. Even at the foremost orifices, the pressure is 
observed to increase by a factor of approximately five. A similar pressure rise is noted for the sidewall pressure distribution shown in Figure 11b.

The effects of inlet unstart on the external flow field are evident by comparison of the schlieren photographs of both started and unstarted inlet configurations (Fig. 12). Figure 12a shows the $30^{\circ}$ sidewalls set to a contraction ratio of 3 with the cowl at $0 \%$. Based on the pressure distribution (Fig. 7) which indicates reflecting oblique shocks, the inlet is started. An oblique shock is observed to emanate from the baseplate leading edge due to the displacement effects of the boundary layer and finite leading edge radius. It is important to recall that the schlieren technique presents an integrated view across the span of the inlet. Twodimensional features (i.e. features which are constant across the width of the inlet) appear in sharp detail, such as the shocks on the underside of the baseplate. Due to the horizontal orientation of the knife edge on the schlieren system, shocks are detected by dark regions (density increases). Interpretation of the schlierens above the inlet is complicated by the fact that the shock waves in this region are skewed relative to the plane of the schlieren. (A small quantity of RTV was placed on the external surface of the cowl to protect the pressure tubing leading from the cowl. A bow shock is visible due to the RTV but is far enough downstream of the cowl lip that it does not appear to interfere with the flow into the inlet.) Figure $12 \mathrm{~b}$ is the unstarted configuration. The baseplate leading edge shock has been pushed forward significantly by the separation on the baseplate and a large amount of flow spillage is now evident. (Note the absence of a strong shock on the RTV for the unstarted configuration.) This unstart was somewhat unexpected for this inlet configuration, and its significance will be addressed in the discussion involving the effect of ratio of specific heats on inlet performance parameters.

Contraction Ratio. Figure 13 demonstrates the effects of contraction ratio on inlet compression as shown by static pressure measurements along the baseplate and sidewall centerline for the baseline configuration at nominal contraction ratios of 3,5 , and 9. As the contraction ratio is increased (sidewalls are brought closer together), the static pressure increases throughout the inlet. This trend agrees with the previous inviscid analysis of the internal shock structure. As the inlet sidewalls are brought closer together, shock crossing and impingement points are moved forward. For a fixed length inlet, the result is an increase in the number of reflected shocks encountered by the flow, thereby increasing overall inlet compression. Since the purpose of the inlet is to compress the gas, this represents a desired result. (However it should be recognized that increasing the contraction ratio also increases concerns with inlet starting.) The movement of the sidewall shock impingements may also have structural implications due to the localized high heating in the impingement region. Table 4 presents the sidewall shock impingement locations for contraction ratios of 3,5 , and 9 based on inviscid modified oblique shock theory.

Leading-Edge Sweep Angle. Sidewalls with both a $30^{\circ}$ and a $70^{\circ}$ leading-edge sweep angle were tested at the baseline configuration to determine experimentally the effects of leading-edge sweep on inlet compression. Modified oblique shock theory predicts an increase in the amount of vertical turning of the flow away from the baseplate and hence an increase in the amount of spillage out of the inlet with an increase in leading-edge sweep. This increase in spillage and decrease in mass capture is manifested in a pressure relief throughout the inlet as seen from the baseplate and sidewall centerline pressure distributions in Figures 14. While the increased spillage with leading-edge sweep generally indicates improved starting performance at low Mach numbers, it also indicates poorer capture at cruise. Increased leadingedge sweep also makes an inlet longer, imposing a size and weight penalty on the inlet

Reynolds Number. Decreasing the Reynolds number indicates by definition that the viscous forces take on greater significance with respect to the momentum forces. Hence, boundary layer thickness is expected to increase and, more importantly to the inviscid flow field, the displacement thickness increases, causing all surfaces to possess effectively larger wedge angles. This in turn generates stronger shocks which increase the internal compression of the inlet. Shock/boundary layer interactions may also become more significant. Figures 15 presents baseplate and sidewall centerline pressure distributions for the baseline configuration at freestream Reynolds numbers of $0.5 \times 10^{6}, 2 \times 10^{6}$, and $4 \times 10^{6}$ per foot. Decreased Reynolds number is observed to yield increased static pressures throughout the inlet. The accompanying forward shift of shock impingement points (due to increasing shock angles) can be seen most notably at the first sidewall impingement region. In other regions the instrumentation density is insufficient to determine the existence or extent of the shock movement.

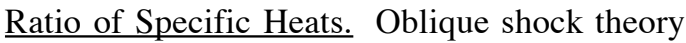
indicates that as the ratio of specific heats is decreased, smaller shock angles will result, yielding a decrease in overall inlet compression. Figure 16 shows experimental pressure data in air $(\gamma=1.4)$ and $\mathrm{CF}_{4}$ $(\gamma=1.22)$ which exhibit this behavior for a contraction ratio of 3, a cowl position of $0 \%$, and a Reynolds number of $0.5 \times 10^{6}$. The pressure is now nondimensionalized as a pressure coefficient, $\mathrm{C}_{\mathrm{p}}$, to account for the $\gamma$ difference between the two test gases. 
At a contraction ratio of 5 , a decrease in pressure again accompanies a decrease in the ratio of specific heats as shown in Figure 17, but a significant difference in the magnitude of the pressure decrease is noted. In the throat entrance region $\left(\mathrm{x}^{\prime} / \mathrm{Tx}^{\prime}=0.95\right)$, a $50 \%$ difference in the pressure values along the baseplate at a contraction ratio of 3 (Fig. 16) has increased to a $150 \%$ difference at a contraction ratio of 5 (Fig. 17). This large pressure difference at a contraction ratio of 5 is likely due to the presence of a large scale separation on the baseplate of the inlet tested in air. The oil flow for this configuration (Figure 18) shows flow on the baseplate feeding forward ahead of the inlet sidewalls, also indicating a large scale separation.

Figure 19 shows that for the inlet tested in air, the forward location of the cowl (25\% position) is observed to be sufficient to cause the internal flow to progress from separated to unstarted. The significance of this progression of conditions for decreasing specific heats ratio lies not in the difference in the magnitudes of the pressure decreases but in the starting characteristics of this inlet exhibited by the two curves in both Figures 19a and 19b. For the same inlet geometry, tested at the same Mach number and Reynolds number, the inlet starts in $\mathrm{CF}_{4}$ and unstarts in air. (The only difference in test conditions was found to be the back pressure, which was higher in $\mathrm{CF}_{4}$ than in air, eliminating that as a factor in the unstart.) From the starting behavior of this inlet in the two test gases, it can be concluded that if an inlet is started in perfect gas air, then the presence of real gas effects, simulated by the decrease in $\gamma$, will not lead to an inlet unstart. These results can be directly applied to hypersonic testing in ground-based test facilities. A major concern in many hypersonic air facilities is the inability to simulate real gas effects. Testing in $\mathrm{CF}_{4}$ simulates the decrease in ratio of specific heats observed at high temperatures in air and is therefore a technique used to simulate real gas effects. Based on the results of this study, it can be said that testing in a perfect gas air facility is conservative with regard to inlet starting predictions; that is, if a certain inlet configuration has started for a given set of flow conditions in a groundbased air facility, the presence of real gas effects will not induce an unstart.

\section{Concluding Remarks}

Two generic sidewall compression scramjet inlets with leading-edge sweep angles of 30 and 70 degrees were tested in Mach 6 air $(\gamma=1.4)$ at Reynolds numbers of $0.5 \times 10^{6}, 2 \times 10^{6}$, and $4 \times 10^{6}$ per foot at various contraction ratios and cowl positions to determine the effects of geometry and Reynolds number on inlet performance characteristics. Data from the present study was compared with data previously obtained for the same models in Mach $6 \mathrm{CF}_{4}(\gamma=1.22)$ to investigate the effect of ratio of specific heats on inlet performance characteristics. Increasing the contraction ratio (moving the sidewalls closer together) increases the number of internal shock reflections and hence incrementally increases the sidewall pressure distribution. The primary effect of moving the cowl forward is capturing the flow which would have otherwise spilled out ahead of the cowl. A combination of increased contraction ratio and a forward cowl placement was found to induce an unstart in Mach 6 air. An increase in sidewall leading-edge sweep angle yields a lower inlet compression and larger spillage angle. A decrease in Reynolds number was found to increase globally the internal pressure distributions by means of increased displacement effects despite the small range of Reynolds numbers over which the models were tested.

The effect of ratio of specific heats on inlet performance parameters was found to be significant. For all configurations a decrease in the ratio of specific heats was found to produce a decrease in the overall pressure levels throughout the inlet. More importantly, for the same model configuration $(\mathrm{CR}=5$, Cowl $=25 \%)$ and the same test conditions $(M=6$, $\left.\mathrm{Re}=0.5 \times 10^{6}\right)$, tests in $\mathrm{CF}_{4}$ at a ratio of specific heats of 1.22 yielded a started inlet, while results for air at a ratio of specific heats of 1.4 yielded an unstarted inlet. From the starting behavior of this inlet in the two test gases, it can be concluded that if an inlet is started in perfect air, then the presence of real gas effects, simulated by the decrease in $\gamma$, will not lead to an inlet unstart. Testing in a perfect gas air facility is therefore conservative with regard to inlet starting predictions; that is, if a certain inlet configuration has started for a given set of flow conditions in a ground-based air facility, the presence of real gas effects will not induce an unstart. 


\section{$\underline{\text { References }}$}

1. Williams, R. M.: National Aero-Space Plane: Technology for America's Future. Aerospace America, Nov. 1986, p. 18.

2. Kandebo, Stanley W.: "Researchers Pursue X-30 Spaceplane Technologies for 1990 Evaluation." Aviation Week and Space Technology, August 8, 1988, pp. 49-53.

3. Henry, John R. and Anderson, Griffin Y.: Design Considerations for the Airframe-Integrated Scramjet. NASA TM X-2895, Dec. 1973.

4. Kumar, A., Singh, D.J., and Trexler, C.A.: A Numerical Study of the Effects of Reverse Sweep on Scramjet Inlet Performance. J. Propulsion and Power, Vol. 8, No. 3, May-June 1992, pp. 714-719.

5. Northam, G. Burton and Anderson, G. Y.: Supersonic Combustion Ramjet Research at Langley. AIAA 24th Aerospace Sciences Meeting, Jan. 6-9, 1986, Reno, NV, AIAA-86-1744.

6. Trexler, Carl A.: Performance of an Inlet for an Integrated Scramjet Concept. J. Aircraft, Vol. 11, No. 9, September 1974.

7. Trexler, Carl A.: Inlet Performance of the Integrated Langley Scramjet Module (Mach 2.3 to 7.6). AIAA/SAE 11th Propulsion Conference, Sept. 29-Oct. 1, 1975, Anaheim, CA, AIAA-75-1212.

8. Trexler, Carl A. and Souders, Sue W.: Design and Performance at a Local Mach Number of 6 of an Inlet for an Integrated Scramjet Concept. NASA TN D-7944, August 1975.

9. Trexler, Carl A.: Inlet Starting Predictions for Sidewall-Compression Scramjet Inlets. AIAA/SAE/ASME/ASEE 24th Joint Propulsion Conference, Boston, MA, July 11-13, 1988. AIAA88-3257.

10. Trexler, Carl A.: Tests of Two SidewallCompression Scramjet Inlets at Mach 18.1 to 21.6 in Helium. NASP TM 1018, May 1988.

11. Holland, Scott D. and Perkins, John N.: Internal Shock Interactions in Propulsion/Airframe Integrated Three-Dimensional Sidewall Compression Scramjet Inlets. 28th AIAA/SAE/ASME/ASEE Joint Propulsion Conference, July 6-8, 1992, Nashville, TN, AIAA-92-3099.

12. Holland, Scott D. and Perkins, John N.: Mach 6 Testing of Two Generic Three-Dimensional Sidewall
Compression Scramjet Inlets in Tetrafluoromethane. AIAA 28th Aerospace Sciences Meeting, January 8-11, 1990, Reno, NV, AIAA-90-0530.

13. Hodge, Jeffrey S.: The Langley 15-Inch Mach 6 High Temperature Tunnel. AIAA 17th Aerospace Ground Testing Conference, July 6-8, 1992, Nashville, TN, AIAA-92-3938.

14. Kutschenreuter, Paul H., Jr., et al.: Investigation of Hypersonic Inlet Shock-Wave Boundary Layer Interaction, Part II: Continuous Flow Test and Analyses. General Electric Company, Technical Report AFFDL-TR-65-36, March 1965 (Part II available AD 636 981, N66-38399).

Table 1: 15-inch Mach 6 Flow Conditions

\begin{tabular}{|lrcc|}
\hline $\mathrm{Re} / \mathrm{ft}$ & $.5 \times 10^{6}$ & $2 \times 10^{6}$ & $4 \times 10^{6}$ \\
$\mathrm{p}_{\infty}(\mathrm{psi})$ & .03 & .08 & .15 \\
$\mathrm{~T}_{\infty}\left({ }^{\circ} \mathrm{R}\right)$ & 150 & 120 & 110 \\
$\mathrm{q}_{\infty}(\mathrm{psi})$ & .75 & 2.0 & 3.7 \\
$\mathrm{p}_{\mathrm{t}, 2}(\mathrm{psi})$ & 1.4 & 3.6 & 6.9 \\
$\mathrm{~T}_{\mathrm{t}, 2}\left({ }^{\circ} \mathrm{R}\right)$ & 1200 & 970 & 925 \\
$\mathrm{M}_{\infty}$ & \multicolumn{2}{c}{6} & \\
$\gamma$ & \multicolumn{2}{c}{1.4} \\
\hline
\end{tabular}


Table 2: Scramjet Inlet Test Matrix $\left(\Lambda=30^{\circ}\right.$.

\begin{tabular}{|l|ll|}
\hline$\Lambda=30^{\circ} \cdot$ & $0 \%$ Cowl & $25 \%$ Cowl \\
\hline & $\begin{array}{l}0.5 \times 10^{6} \\
\text { CR }=3\end{array}$ & \\
& $4.0 \times 10^{6} \times 10^{6}$ & $0.5 \times 10^{6}$ \\
CR $=5$ & $0.5 \times 10^{6}$ & $0.5 \times 10^{6}$ \\
& & \\
$\mathrm{CR}=9$ & $0.5 \times 10^{6}$ & \\
\hline
\end{tabular}

Table 3: Scramjet Inlet Test Matrix $\left(\Lambda=70^{\circ} \cdot\right)$

\begin{tabular}{|l|ll|}
\hline$\Lambda=70^{\circ} \cdot$ & $0 \%$ Cowl & $25 \%$ Cowl \\
\hline & $0.5 \times 10^{6}$ & \\
& $2.0 \times 10^{6}$ & $0.5 \times 10^{6}$ \\
& $4.0 \times 10^{6}$ & \\
$\mathrm{CR}=5$ & $0.5 \times 10^{6}$ \\
& \\
$\mathrm{CR}=9$ & $0.5 \times 10^{6}$ \\
\hline
\end{tabular}

Table 4: Modified Inviscid Oblique Shock Theory Predictions for Incident Shock Locations

\begin{tabular}{|l|cc|}
\hline$\Lambda=30^{\circ} \cdot$ & $\begin{array}{c}\text { Shock reflecting } \\
\text { at centerline } \\
\mathrm{x}^{\prime} / \mathrm{Tx}^{\prime}\end{array}$ & $\begin{array}{c}\text { Shock incident } \\
\text { on sidewall } \\
\mathrm{x}^{\prime} / \mathrm{Tx}^{\prime}\end{array}$ \\
\hline $\mathrm{CR}=3$ & $0.624 \square$ & 0.867 \\
$\mathrm{CR}=5$ & $0.522 \square$ & 0.719 \\
$\mathrm{CR}=9$ & $0.470 \square$ & 0.647 \\
\hline
\end{tabular}
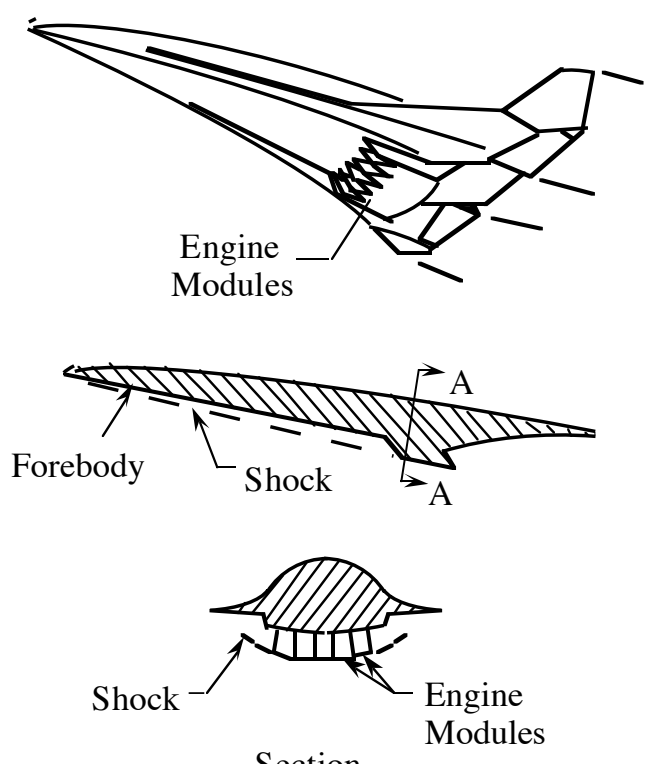

Section

A-A

Figure 1. Propulsion-Airframe Integration Concept

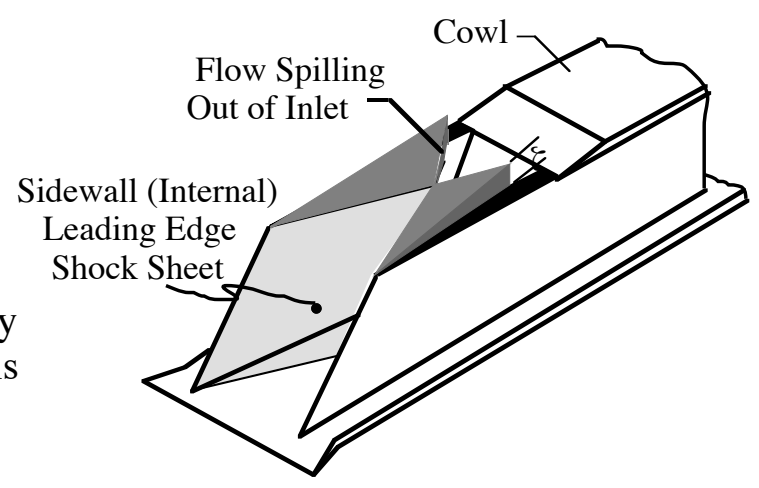

Figure 2. Three Dimensional Sidewall Compression Scramjet Inlet Showing Region of Upturned Flow Due to the Internal Leading Edge Shock

(Additional spillage due to the reflected shock is not shown; the spillage angle $\zeta$ is exaggerated) 
Photo ID: NASA L-92-1782

(a) $30^{\circ}$ Inlet Model

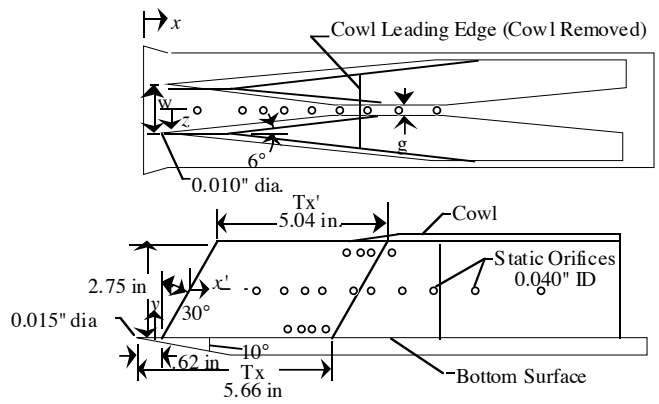

(a) 30 Degree Configuration (Baseline)
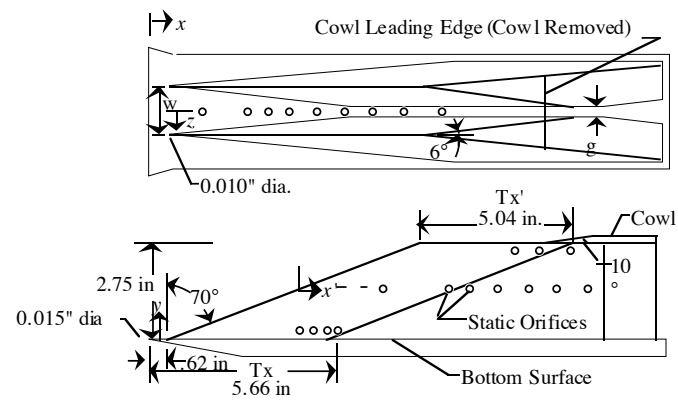

(b) 70 Degree Configuration

Figure 4. Dimensioned Drawings of the $30^{\circ}$ and $70^{\circ}$ Leading Edge Sweep Configurations

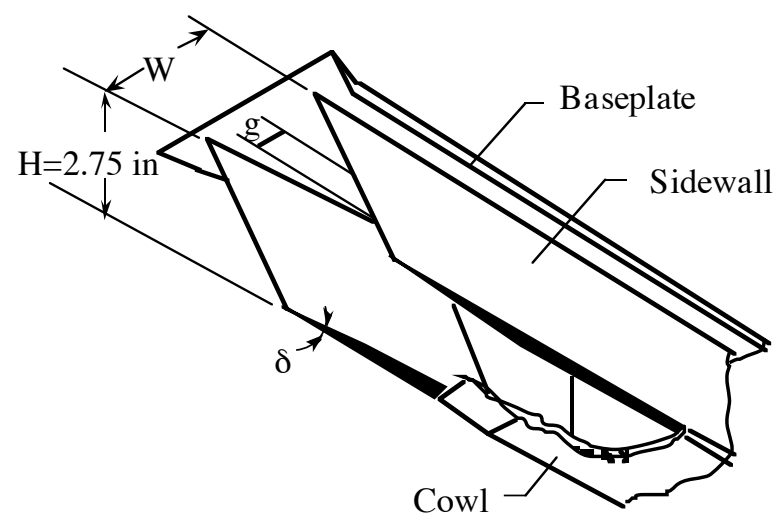

Figure 5. Inlet Model Shown in Flight Orientation 


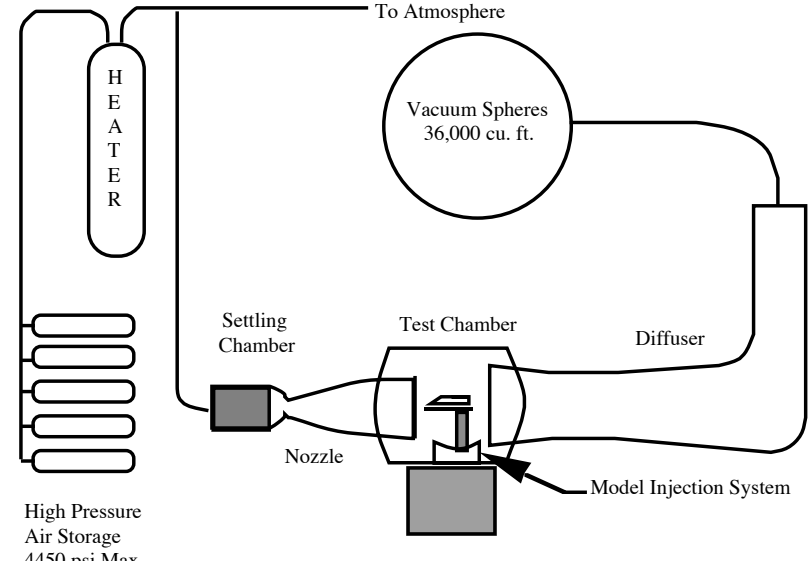

Figure 6. Schematic of 15-Inch Mach 6 Tunnel

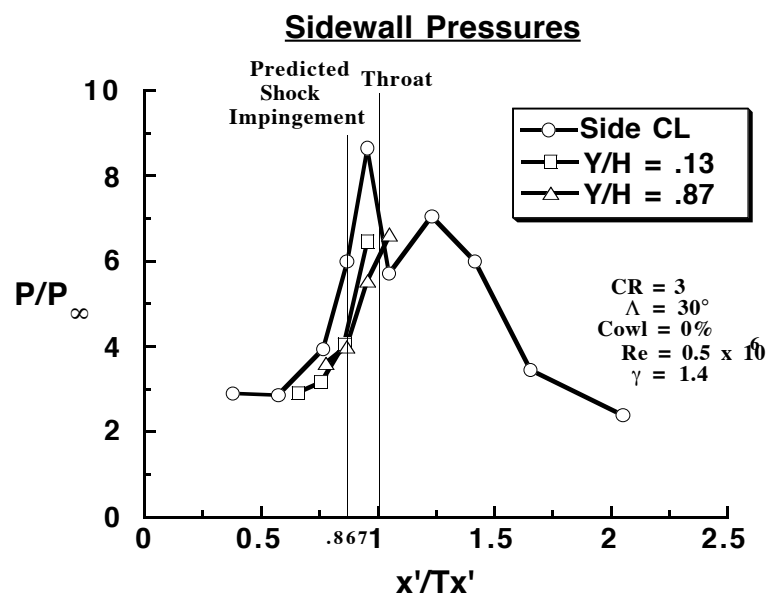

Figure 7. Baseline Configuration

Figure 8. Oil Flow of Inlet Sidewall in Air (Arrow Indicates Shock Impingement Region)

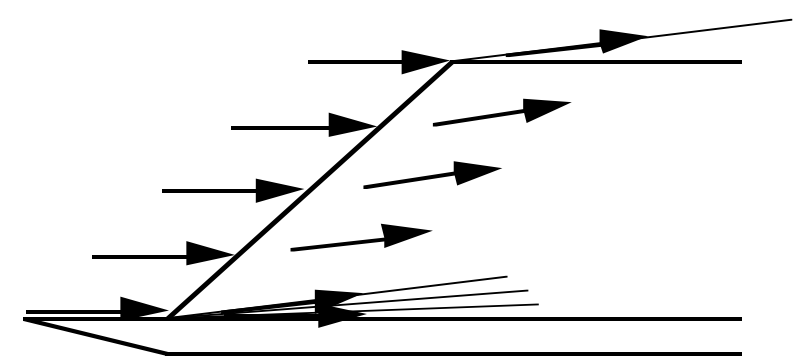

Figure 9. Centered Expansion Model of Baseplate Interaction Region

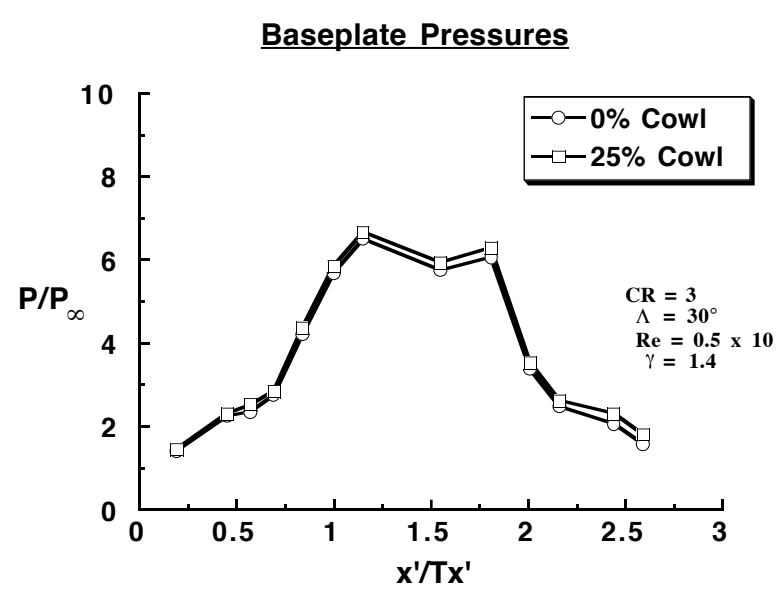

Figure 10(a). Cowl Position Effects

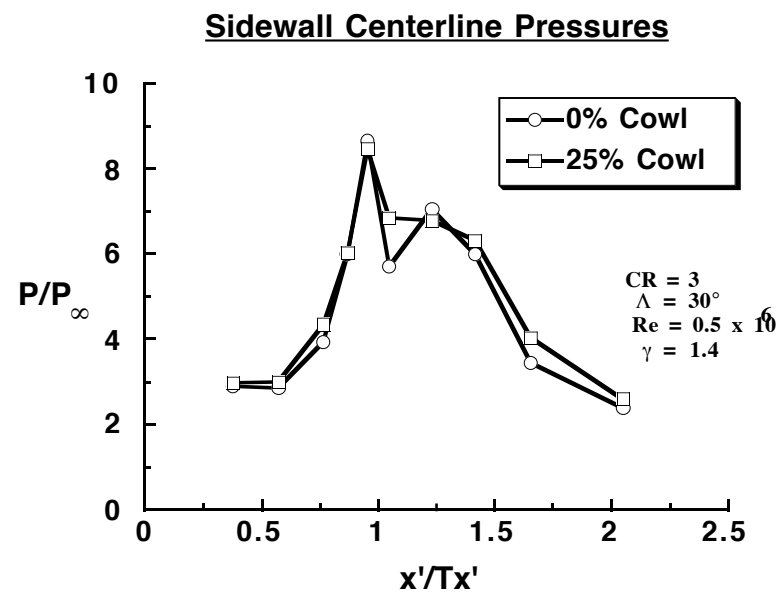

Figure 10(b). Cowl Position Effects 


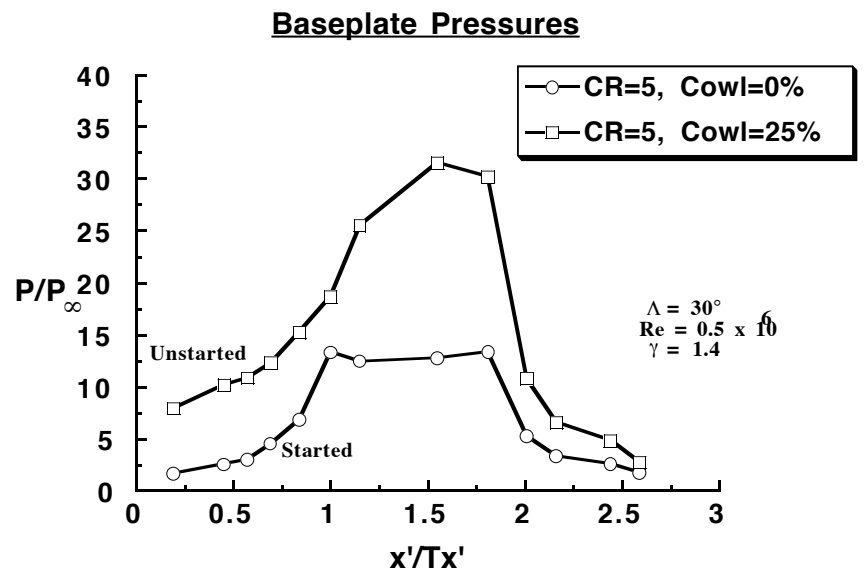

Figure 11(a). Pressure Distributions for Started and Unstarted Configurations

Figure 12(b). Schlieren of Unstarted Inlet

\section{Sidewall Centerline Pressures}

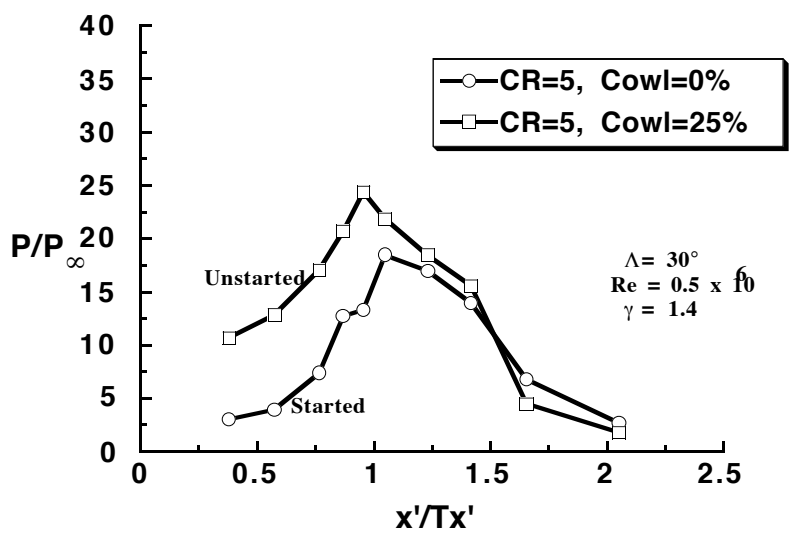

Figure 11(b). Pressure Distributions for Started and Unstarted Configurations

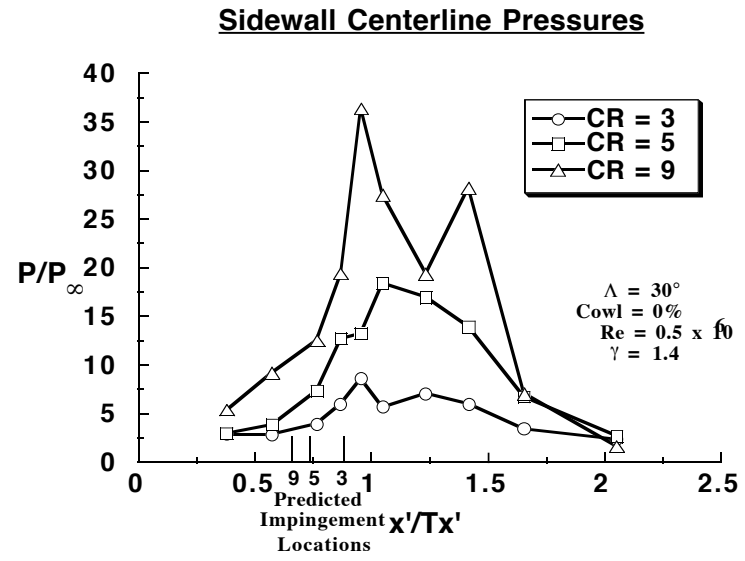

Figure 13(a). Contraction Ratio Effects

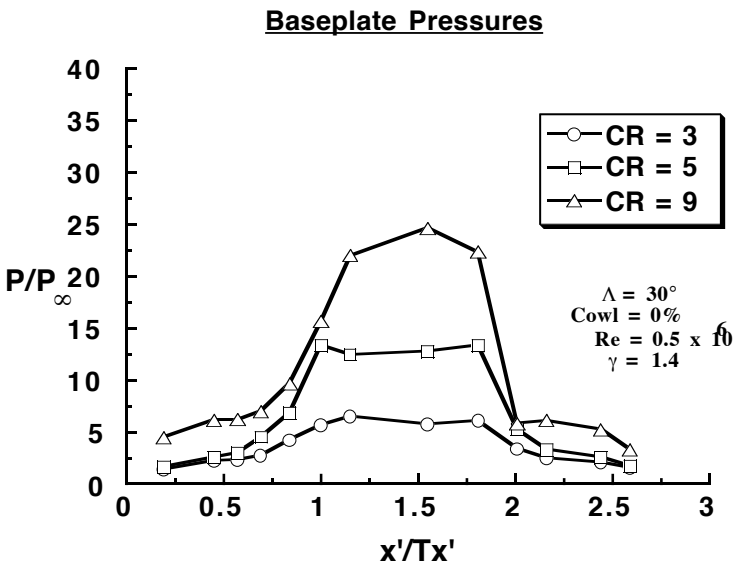

Figure 12(a). Schlieren of Started Inlet

Figure 13(b). Contraction Ratio Effects 


\section{Baseplate Pressures}

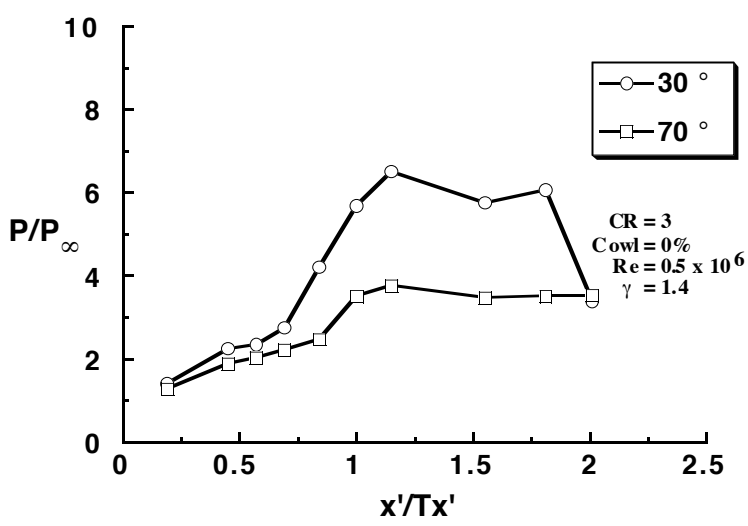

Figure 14(a). Leading-Edge Sweep Effects

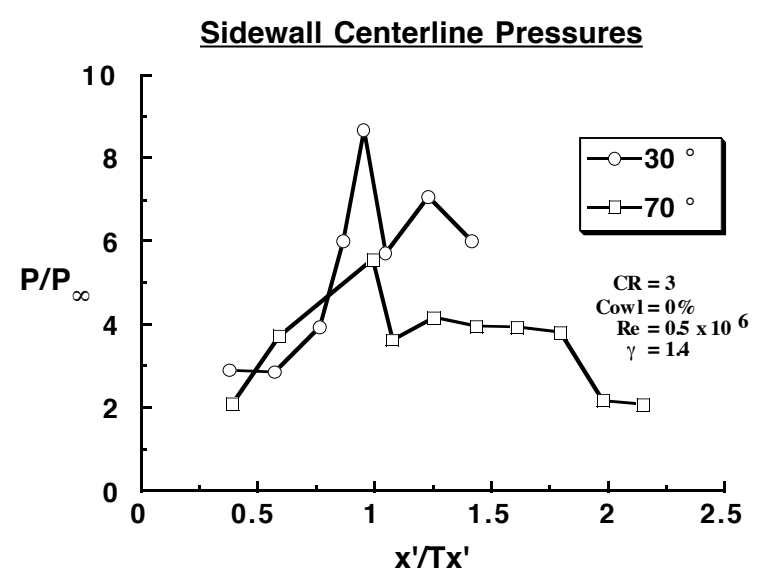

Figure 14(b). Leading-Edge Sweep Effects

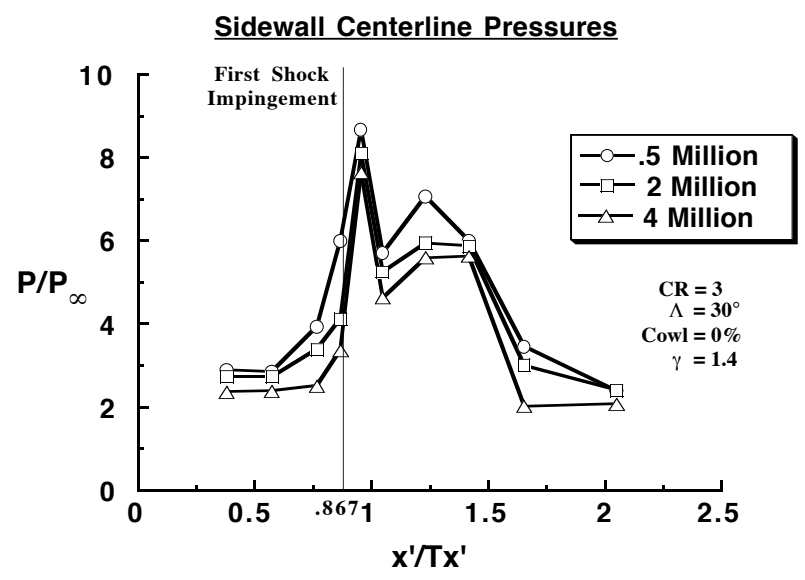

Figure 15(a). Reynolds Number Effects

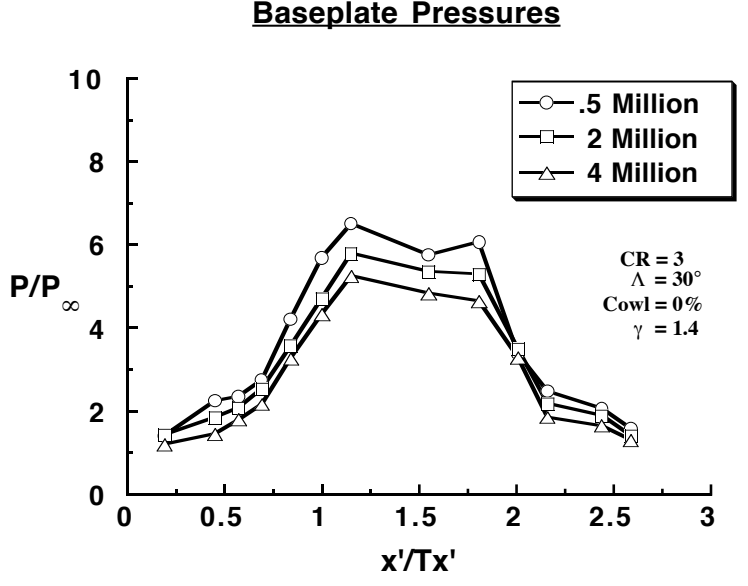

Figure 15(b). Reynolds Number Effects

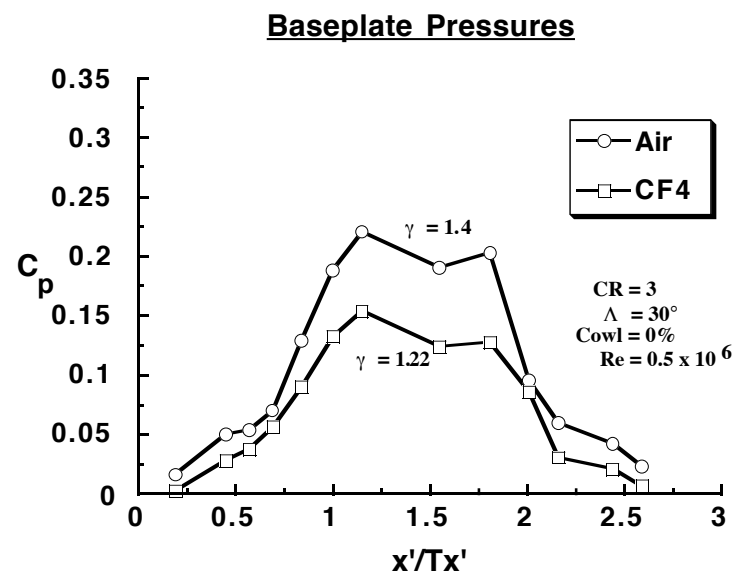

Figure 16(a). Effect of Ratio of Specific Heats

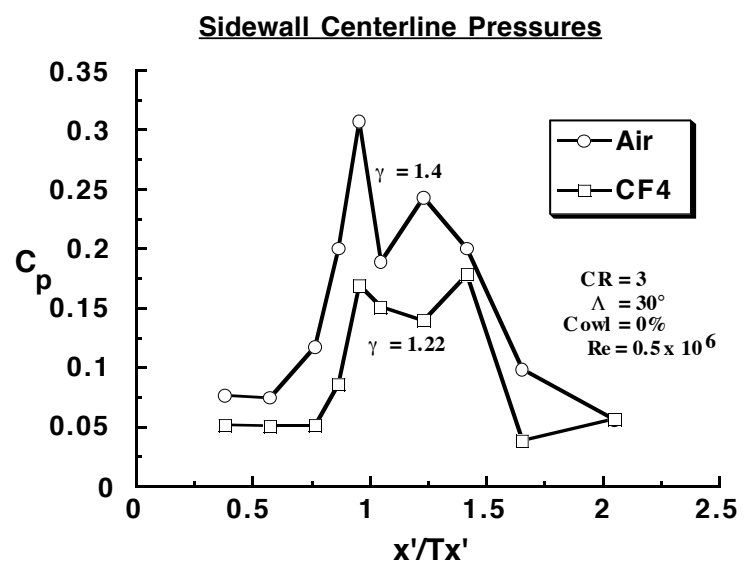

Figure 16(b). Effect of Ratio of Specific Heats 


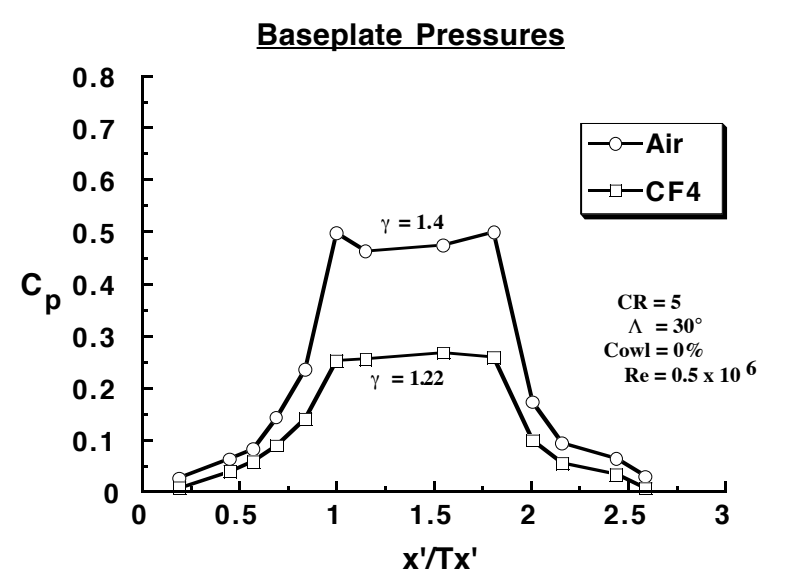

Figure 17(a). Effect of Ratio of Specific Heats

\section{Sidewall Centerline Pressures}

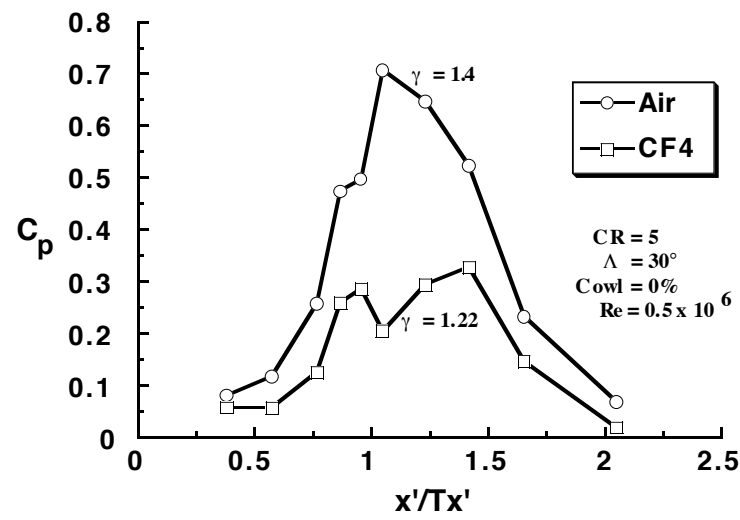

Figure 17(b). Effect of Ratio of Specific Heats

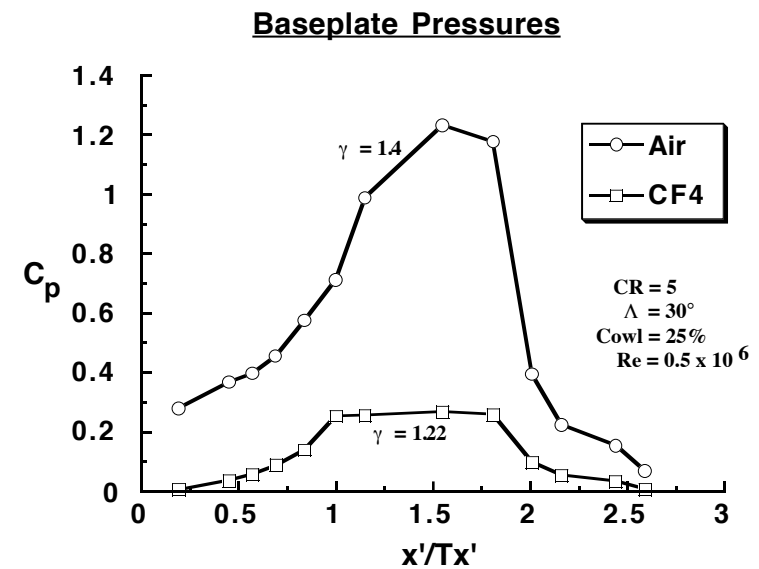

Figure 19(a). Effect of Ratio of Specific Heats

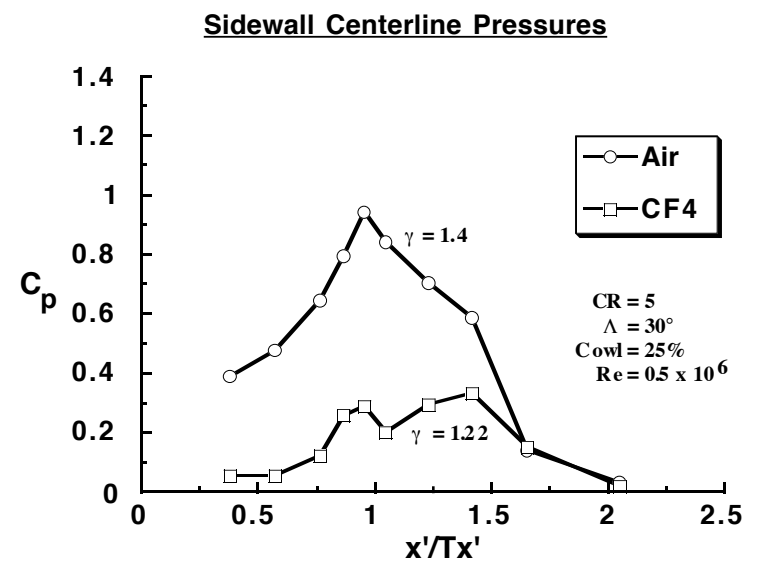

Figure 19(b). Effect of Ratio of Specific Heats

Figure 18. Oil Flow of Inlet Baseplate and Sidewall in Air (Arrow Indicates Large Scale Separation on Baseplate) 